\title{
Peptic ulceration of the oesophagus following corrosive burns
}

\author{
J OSEPH IMRE AND GEOFFREY W O L ER \\ From the 1st Surgical Clinic, Medical University, Szeged, Hungary, and the \\ General Infirmary at Leeds, Leeds, Yorkshire
}

Ten cases of combined corrosive and peptic strictures of the oesophagus have been described. The peptic stricture of the oesophagus occurred 20 to 50 years after the corrosive burn. The authors believe that the hiatal hernia was due to the contraction of the fibrotic wall of the oesophagus, and therefore they prefer to call it a traction hiatal hernia. The operation of choice in these cases is the resection of the fibrotic oesophagus and replacement by jejunal loop or colic segment. There has been no mortality in this series of 10 patients.

A sliding hiatal hernia may cause reflux oesophagitis due to incompetence of the cardia which accompanies this type of hernia (Allison, 1951; Barrett, 1950). The oesophagitis may progress into peptic ulceration which destroys the oesophageal wall and results in fibrosis, contraction, and stricture formation. The contracted segment of oesophagus now holds the hernia permanently in the chest because shortening of the oesophagus has taken place.

When the acute inflammatory process has subsided after swallowing a corrosive fluid, the oesophageal wall becomes fibrotic and contracts, pulling up into the chest a pouch of stomach which we prefer to describe as a traction hiatal hernia. The fibrosed oesophageal wall usually remains open with a fixed and narrowed lumen.

The patient, having recovered from the intense dysphagia during the acute period, learns himself what he can swallow without difficulty through this narrow segment of oesophagus, and indeed he may continue so for many years without complaints.

During this time, however, reflux oesophagitis occurs in the lower segment of the oesophagus distal to the corrosive stricture, and in this lower portion produces a peptic stricture (Fig. 1).

Many years may elapse after the apparent healing of a corrosive stricture before the patient again presents with dysphagia. He complains of dysphagia only when the peptic stricture becomes narrower than the corrosive stricture.

During the past 10 years, 10 patients ( 8 from Szeged and 2 from Leeds) have had surgical treatment for peptic stricture 20 to 50 years after $\stackrel{\mathbb{D}}{-}$ they had a corrosive burn (Table).

It is therefore our opinion that it takes this. period of time for a traction hiatal hernia and peptic ulceration to develop.

All our patients have been treated by resection of the fibrotic segment of oesophagus and re- $\frac{\not}{\varnothing}$ placement by an interposed loop of jejunum or $\cong$ colon, except one who had a B type haemophilia $\vec{F}$ and on whom we removed only the stenosed 3 pyloric part of the stomach (Fig. 2).

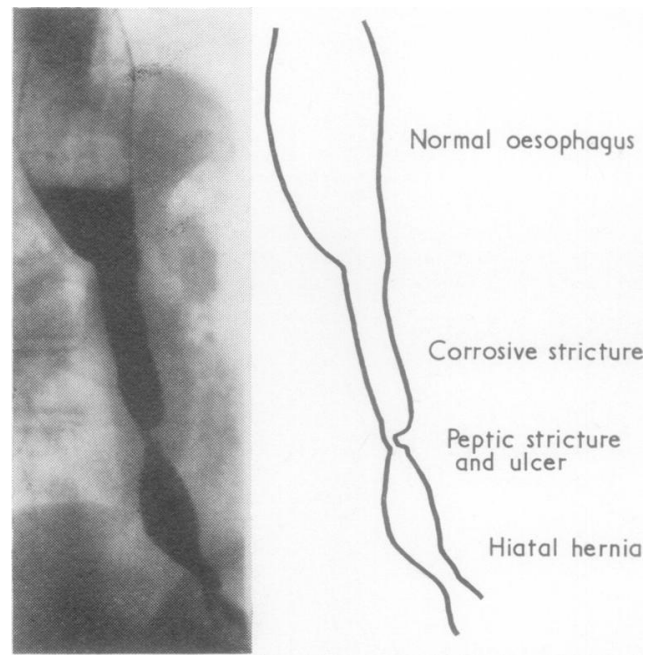

FIG. 1. Gy.L., 67-year-old man, 30 years after corrosive burn developed traction hiatal hernia, peptic stricture, $\stackrel{\mathbb{Q}}{\circ}$ and ulcer. 

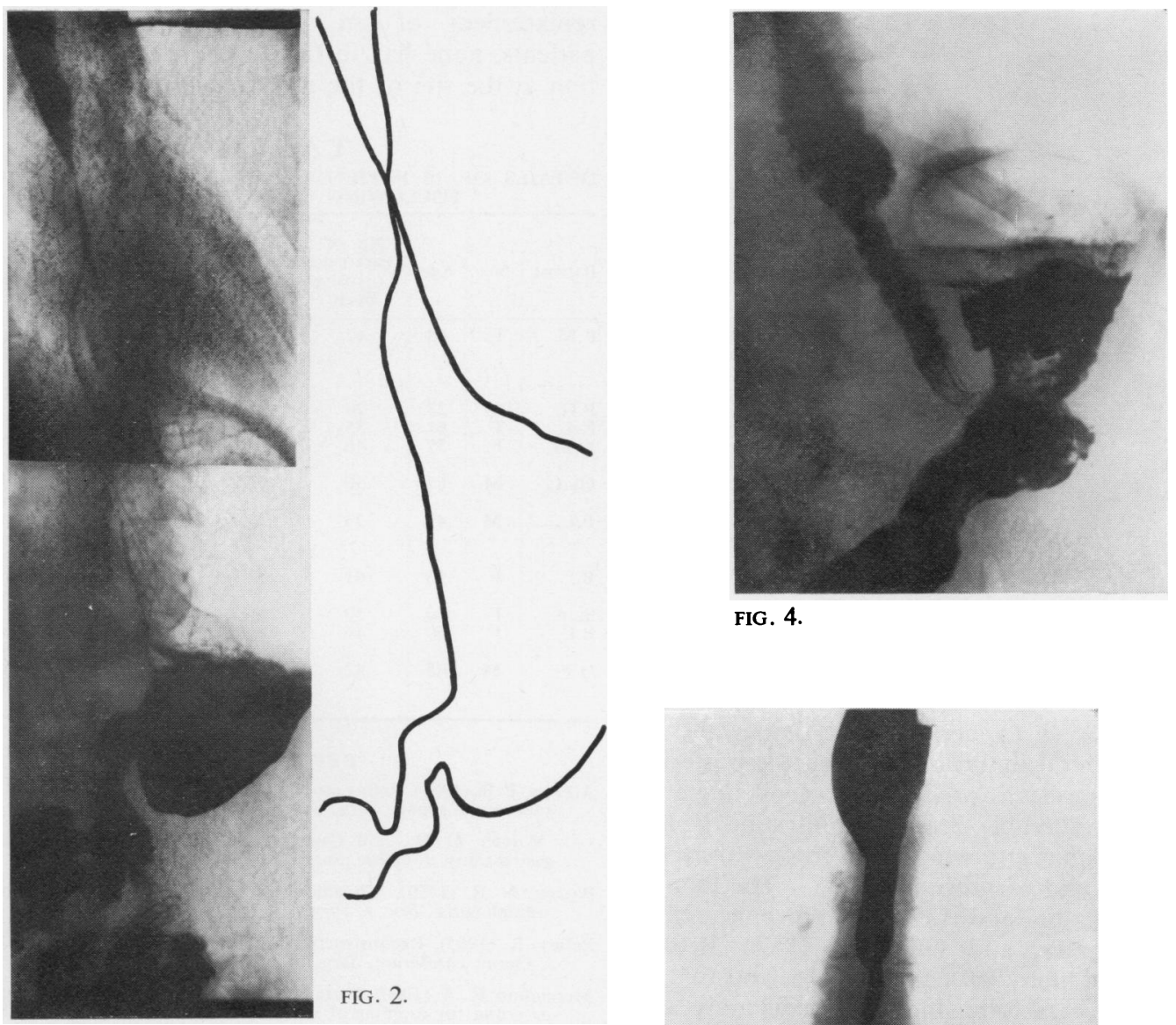

FIG. 4.

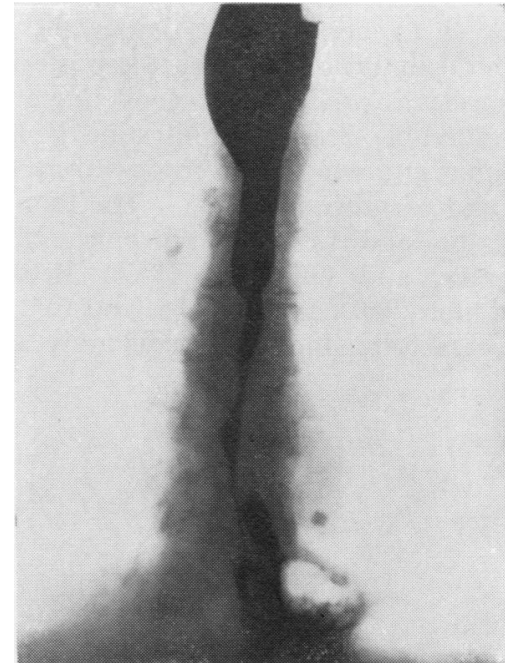

FIG. 5 .

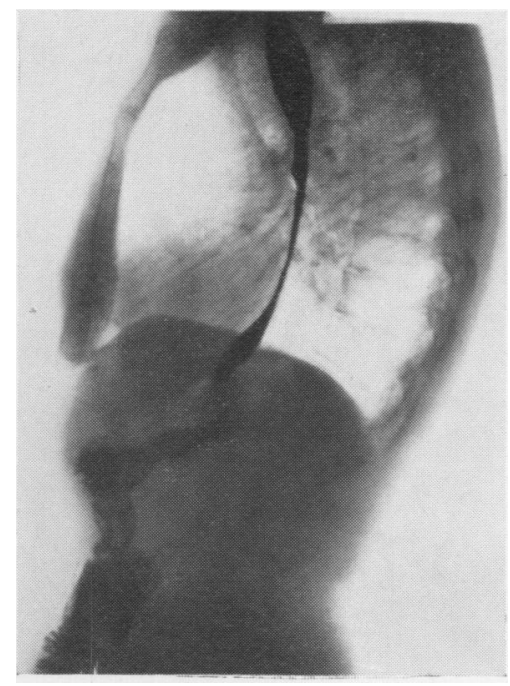

FIG. 3 .

FIG. 2. F.L., 41-year-old man, 33 years after corrosive burn. The antral part of the stomach is narrowed, and there is a traction hiatal hernia and stricture of the lower part of the oesophagus. Treated by partial gastrectomy Billroth I because of B type haemophilia, and had considerable relief from dysphagia post-operatively.

FIG. 3. N.M., 57-year-old woman, 46 years after corrosive burn.

FIG. 4. Same patient as in Fig. 3, after resection and colonic replacement of the oesophagus.

FIG. 5. Sz.A., 60-year-old woman, 50 years after corrosive burn. 


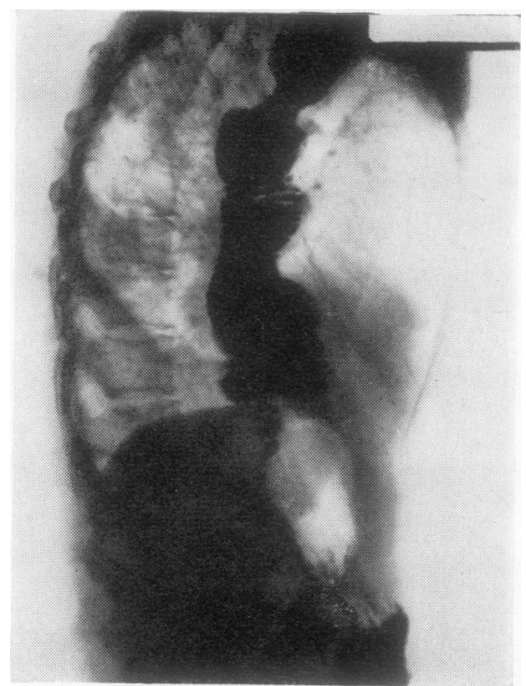

FIG. 6. Same patient as in Fig. 5: after jejunal replacement of the oesophagus.

One of us (J. I.) considers it important to anastomose the jejunum or colon to the posterior wall of the stomach, producing a good angle of entry. A considerable length of intestine is left below the diaphragm, which is compressed as the stomach fills and so prevents reflux. The loop is also isoperistaltic and this too prevents reflux (Allison, Wooler, and Gunning, 1957 ; Belsey, 1965 ; Merendino, 1960) (Figs 3, 4, 5, and 6).

Up to 10 years following oesophagectomy and replacement of an interposed loop in nime patients, none has so far developed peptic ulcer tion at the site of the gastric anastomosis.

T A B L E

ڤ DETAILS OF 10 PATIENTS WITH PEPTIC ULCERATIQ
FOLLOWING CORROSIVE BURNS

\begin{tabular}{|c|c|c|c|c|c|c|}
\hline Patient & Sex & Age & 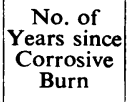 & $\underset{\text { (yrs) }}{\text { Dysphagia }}$ & $\begin{array}{l}\text { Date of } \\
\text { Surgery }\end{array}$ & $\begin{array}{c}\text { Type od } \\
\text { Operatiof }\end{array}$ \\
\hline E.M. & F & 48 & 47 & 20 & 27.1 .59 & $\begin{array}{r}\text { Oesophages } \\
\text { tomy and } \\
\text { jejunal re } \\
\text { placemeg }\end{array}$ \\
\hline $\begin{array}{l}\text { P.H. } \\
\text { K.L. } \\
\text { N.M. }\end{array}$ & $\begin{array}{l}\mathrm{M} \\
\mathrm{F} \\
\mathrm{F}\end{array}$ & $\begin{array}{l}27 \\
61 \\
57\end{array}$ & $\begin{array}{l}20 \\
35 \\
46\end{array}$ & $\begin{array}{l}4 \\
5 \\
6\end{array}$ & $\begin{array}{c}30.6 .64 \\
23.10 .69 \\
31.1 .67\end{array}$ & C'olonic re \\
\hline Gy.L. & $\mathbf{M}$ & 67 & 30 & $6 / 12$ & 13.2.68 & $\begin{array}{l}\text { placer } \\
\text { Jejunal }\end{array}$ \\
\hline F.L. & $\mathbf{M}$ & 41 & 33 & $3 / 12$ & 12.10 .68 & $\begin{array}{l}\text { placemea } \\
\text { Partial gas } \\
\text { trectoms }\end{array}$ \\
\hline B.I. & F & 55 & 41 & $18 / 12$ & 20.1.69 & $\begin{array}{c}\text { Jejunal re } \\
\text { placeme }\end{array}$ \\
\hline $\begin{array}{l}\text { Sz.A } \\
\text { B.E. }\end{array}$ & $\begin{array}{l}\mathrm{F} \\
\mathrm{F}\end{array}$ & $\begin{array}{l}60 \\
60\end{array}$ & $\begin{array}{l}50 \\
46\end{array}$ & $\begin{array}{l}5 / 12 \\
8 / 12\end{array}$ & $\begin{array}{l}19.3 .69 \\
22.4 .60\end{array}$ & Colonic \\
\hline O.P. & $\mathbf{M}$ & 45 & 42 & 5 & 9.5.69 & $\begin{array}{l}\text { placem } \\
\text { placem } \\
\text { placem }\end{array}$ \\
\hline
\end{tabular}

Allison, P. R. (1951). Reflux esophagitis, sliding hiatal hernia, and th anatomy of repair. Surg. Gynec. Obstet., 92, 419.

— Wooler, G. H., and Gunning, A. J. (1957). Esophagojejun gastrostomy. J. thorac. Surg., 33, 738.

Barrett, N. R. (1950). Chronic peptic ulcer of the oesophagus an 'oesophagitis'. Brit. J. Surg., 38, 175.

Belsey, R. (1965). Reconstruction of the esophagus with left colo J. thorac. cardiovasc. Surg., 49, 33.

Merendino, K. A. (1960). Certain considerations in the use of jejunum or colon for esophageal substitution. Amer. J. Surg., 99, 833 